\title{
A Fundamental Study on Imaging with an Off-Axis Fresnel Zone Plate
}

\author{
Gensei ITAYA and Kazuhiko KoJIMA \\ School of Paramedicine, Kanazawa University \\ 5-11-80, Kodatsuno, Kanazawa-shi 920 \\ Received August 12, 1978
}

\begin{abstract}
An off-axis Fresnel zone plate, through use of a halftone screen to introduce a spatial carrier frequency, can be used as a large-area, coded aperture for imaging incoherent radiation sources. This paper discusses the structure of off-axis Fresnel zone plate as an aperture and the method of imaging from the viewpoint of the spatial resolution by optical simulation, appending some examples of objects, holograms and reconstructed images. It is then concluded that the off-axis Fresnel zone plate having $D$ (diameter) $=5.8 \mathrm{~cm}$ and $\nu_{c}$ (spatial center frequency) $=23 \mathrm{l} / \mathrm{cm}$ is sufficient for the reconstructed images.
\end{abstract}

\section{Introduction}

In 1972, H.H. Barrett and D.T. Wilson" reported that an off-axis Fresnel zone plate (F ZP) could be utilized for imaging incoherent radiation sources if a halftone screen was used. Later on there are many reports on Fresnel zone plate imaging. ${ }^{2)}$ 5) In practice, it is important to determine the structure of off-axis FZP from the viewpoint of the lateral spatial resolution of the reconstructed image. In this paper, the structure of off-axis FZP as an aperture and the method of imaging by optical simulation are discussed on the basis of reconstructed images obtained using various off-axis FZPs, together with some examples of objects, holograms and reconstructed images.

\section{Off-Axis Fresnel Zone Plate and Halftone Screen}

Figure 1 shows a quarter of a negative type on-axis FZP. The structure of an on-axis FZP derives from alternate transparent and opaque concentric annular zones except for the first zone, which is a circle. The radius, $r_{n}$ of the $n$-th zone's outer boundary circle is given by

$$
r_{n}=r_{1} \sqrt{n}, \quad n=1,2,3 \cdots \cdots N
$$

where $r_{1}$ is the radius of the first circular zone. The off-axis FZP is fabricated using a part of this on-axis FZP, which is shown as a circle with a diameter $D$ in Fig. 1. The off-axis FZP has the same focal length as the on-axis FZP does, which is given by

$$
f=r_{1}{ }^{2} /(\lambda p), \quad p=1,3 \cdots
$$

where $\lambda$ is the wavelength of monochromatic light.

The spatial center frequency ${ }^{2)}$ is given by

$$
\nu_{c}=r_{c} / r_{1}{ }^{2},
$$

where $r_{\mathrm{c}}$ is the distance from the center of curvature of the FZP zones to the center of the off-axis FZP.

Figure 2(A) and (B) show the external form and the Fourier spectrum of the off-axis FZP used in this study. The right and left side band components are observed symmetrically in the Fourier spectrum, corresponding to $p= \pm 1$. When the off-axis FZP is used for imaging of incoherent source, the half tone screen is necessary to introduce a spatial carrier frequency. This half tone screen consists of alternately transparent and opaque parallel zones. Figure 3(A) and (B) show the external form and the Fourier spectrum of the halftone screen used. This Fourier spectrum shows that the half tone screen consists of discrete frequencies. Figure 4 shows the blockdiagram for obtaining Fourier spectrum of zone plates and half tone screens. Theoretically, the Fourier transform of the half tone screen is written as follows: ${ }^{6)}$ 


$$
H(\nu)=\sum_{p} H_{p} \delta\left(\nu-p \nu_{1 / 2}\right) ;
$$

where $\nu$ is a spatial frequency, $\nu_{1 / 2}$ is the fundamental frequency of the half tone screen, and $H_{p}$ is the $p$-th Fourier coefficient of $H(\nu)$; both $\nu$ and $\nu_{1 / 2}$ are two-dimensional vectors but treated as scalar quantities for simplicity. As in Fig. $3(B)$, the spectrum of even $\operatorname{orders}(p= \pm 2, \pm 4)$, which are theoretically non-existent, is of ten observed in experiments. This is considered to be due to the expansion or contraction and thickness of film base, and indistinctness of the images recorded on film.

\section{Hologram Recording and Image Reconstruction Systems}

Figure 5 shows a hologram recording system, in which an off-axis FZP in Fig. 2(A) and a hatf tone screen in Fig. 3(A) are used. The Fourier spectrums of the FZP and the half tone screen are shown in Fig. 2(B) and Fig. 3(B).

The most important components are the spectrum of $p= \pm 1$, which should coincide with that of the off-axis FZP on the hologram plane when coding, or recording the hologram. This condition, from a simple geometry, is defined as follows: ${ }^{11}$

$$
\nu_{1 / 2} \frac{u}{v}=\nu_{c} \frac{u}{u+v}
$$

Where $u$ and $v$ are the distances from the object to the off-axis FZP and from this FZP to the hologram plane, respectively. In recording the hologram, this condition must be followed, or a good image reconstruction cannot be expected. In this experiment, templates or photographic films are used as the objects; let its intensity distribution be $i$ and the transparency of the half tone screen be $h$, then their product, $i h$ is the intensity distribution of the planar object and half tone screen placed close. Let the transparency of the off-axis FZP be $z$, then the intensity distribution on the hologram plane will be given by

$$
s=z \otimes[i h] \text {. }
$$

In this equation, the symbol " $\otimes$ " denotes a convolution: The Fourier transform of Eq. (6) is given by

$$
S=Z[I \otimes H]
$$

in which the constant term is omitted for clarity. Using Eq. (4) and after tedious calculation $^{1,2)}$, Eq. (7) is rewritten as:

$$
S(\nu)=\sum_{p} H_{p} Z\left[\left(\frac{u+v}{u}\right) \nu\right] I\left[p \nu_{1 / 2}-\left(\frac{u}{v}\right) \nu\right]
$$

The hologram expressed by Eq. (6) is then reduced to about $7 \mathrm{~mm}$ in diameter, from which the image of the object is reconstructed in the image reconstruction system as illustrated in Fig. 6. An example of the object (i), and its hologram (s, Eq. (6)) are shown in Fig. 7(A) and (B).

Figure 8 shows the Fourier spectrum $(S$, Eq. (8)) which consists of a D.C. component at the center, $p= \pm 1$ components and $p= \pm 2$ components, both $p= \pm 1$ and $p= \pm 2$ components containing information on the object. To reconstruct the image, $p=-1$ is focused on the screen using a magnifying lens. The image can be reconstructed from $p=+1$, but more likely to be disturbed by noise (see the surroundings of $p=+1$ in Fig. 8). The image reconstructed from $p=-1$ in Fig. 8 is shown in Fig. $7(\mathrm{C})$. It may be a general practice to place an iris to remove components other than $p=-1$, but the image can be separated and projected onto the screen with an enlarged size of several $\mathrm{cm}$ even if such an iris is not used.

The lateral spatial resolution, on the Rayleigh criterion, of the hologram recording system is given by substituting Eqs. (1), (2) and (3) into $d=\beta_{n}\left(1+\frac{u}{v}\right) r_{1} /(2 \sqrt{n}),{ }^{1,2), 4}$, ,5) which is the lateral spatial resolution in the system using an on-axis FZP, as follows:

$$
d=\beta_{n} \frac{r_{1}^{2}}{D}\left(1+\frac{u}{v}\right)=\beta_{n} \frac{r_{e}}{D \nu_{c}}\left(1+\frac{u}{v}\right)=\beta_{n} \frac{r_{c}}{D \nu_{1 / 2}}
$$

Since the off-axis FZP used as an aperture has a large number of zones, the lateral spatial resolution factor, $\beta_{n}=1.22$ is applicable.4)

\section{Experimental Results}

As understoud from Eq. (9), the smaller $r_{1}$ and the greater $D$, the better is the lateral spatial resolution of the- off-axis FZP. In our experiment, a number of on-axis FZPs, each having a different $r_{1}$ that ranges from 0.5 to $1.5 \mathrm{~cm}$, 

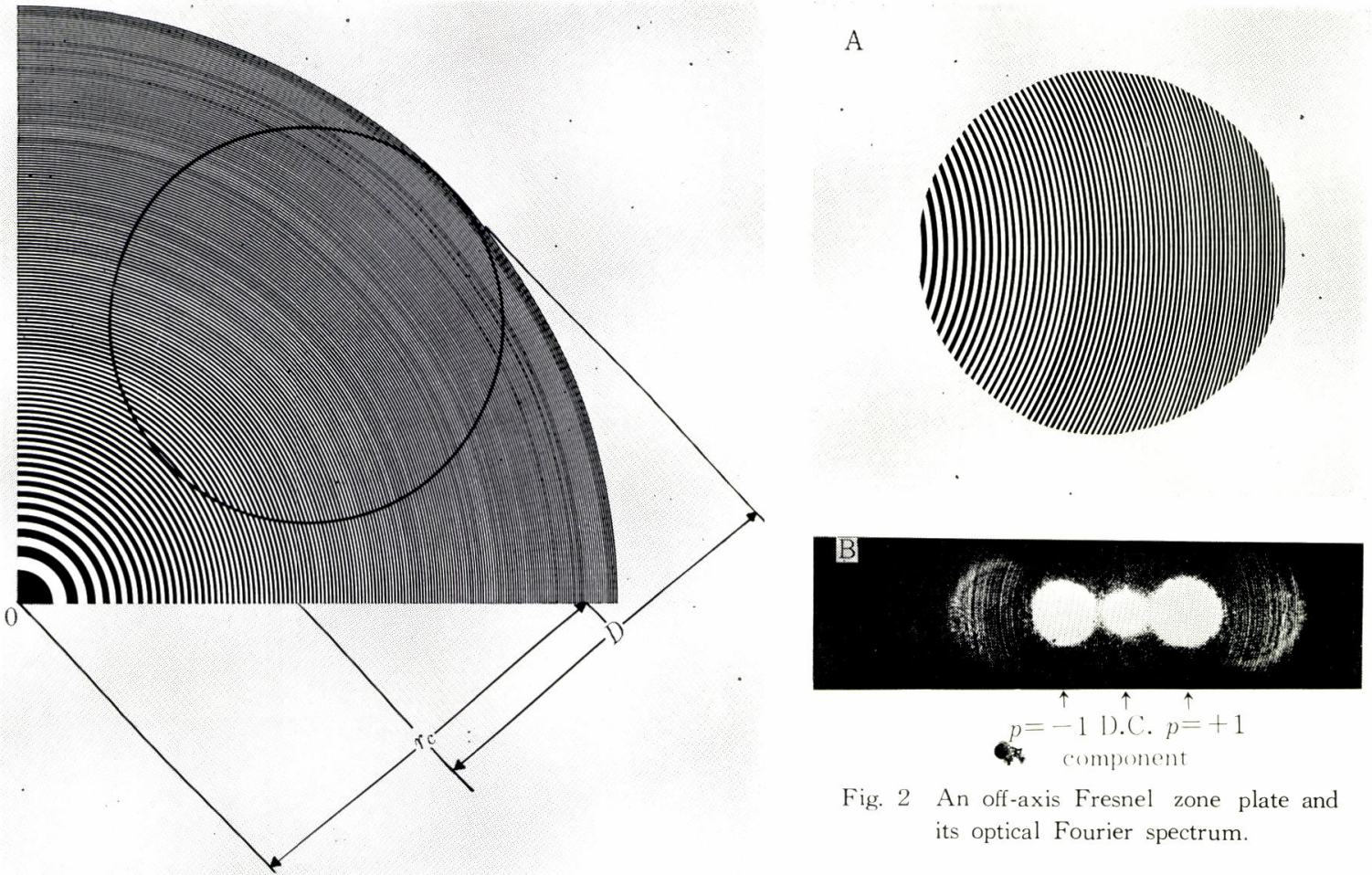

Fig. 2 An off-axis Fresnel zone plate and its optical Fourier spectrum.

Fig. 1 This pattern shows a quarter of a negative on-axis Fresnel zone plate, from which an off-axis Fresnel zone plate (circled) is obtained.
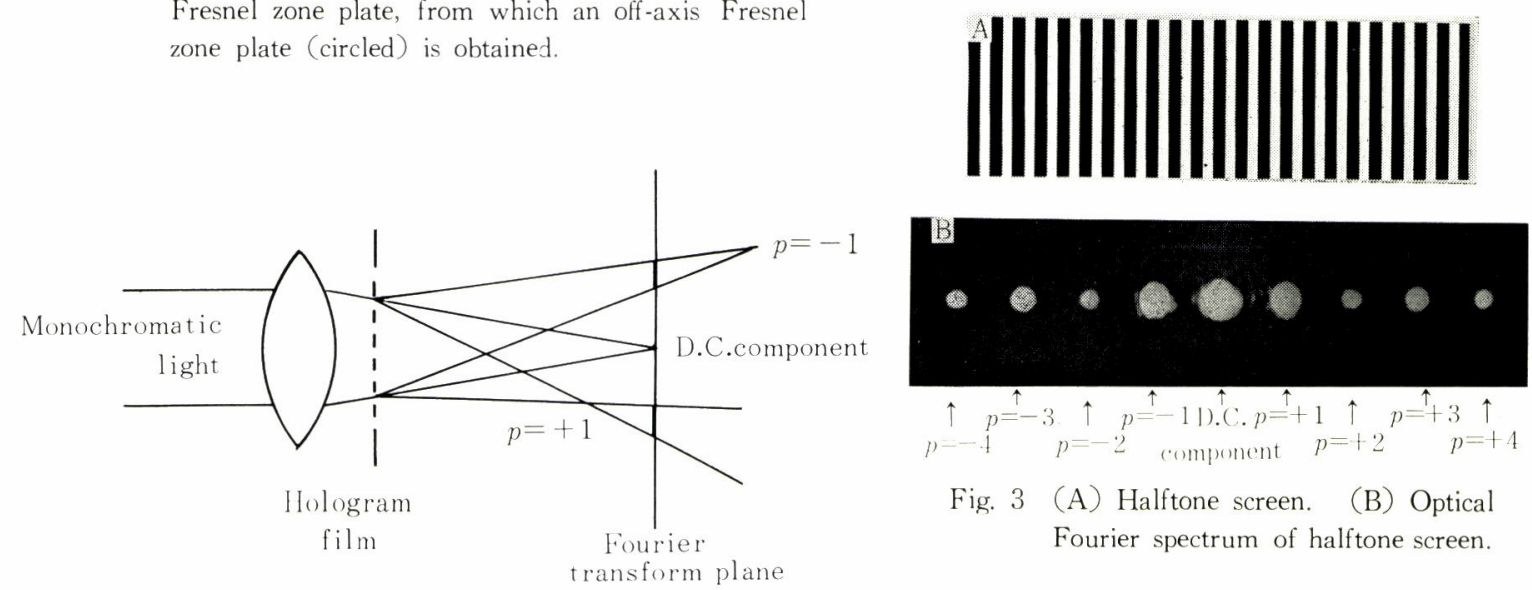

Fig. 3 (A) Halftone screen. (B) Optical Fourier spectrum of half tone screen.

Fig. 4 Blockdiagram for obtaining Fourier spectrum of an off-axis FZP and a halftone screen. 


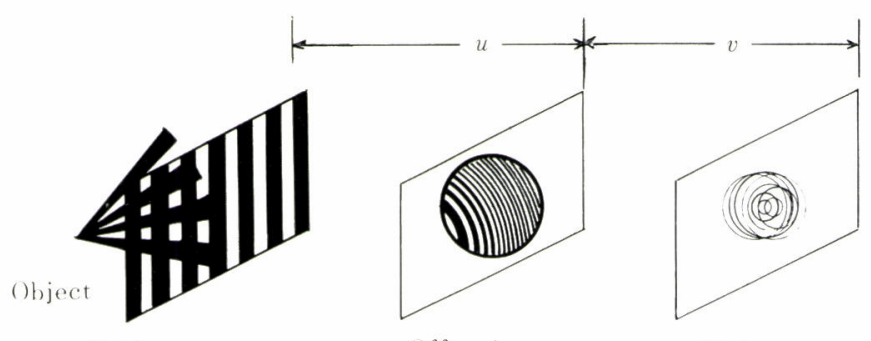

Halftone

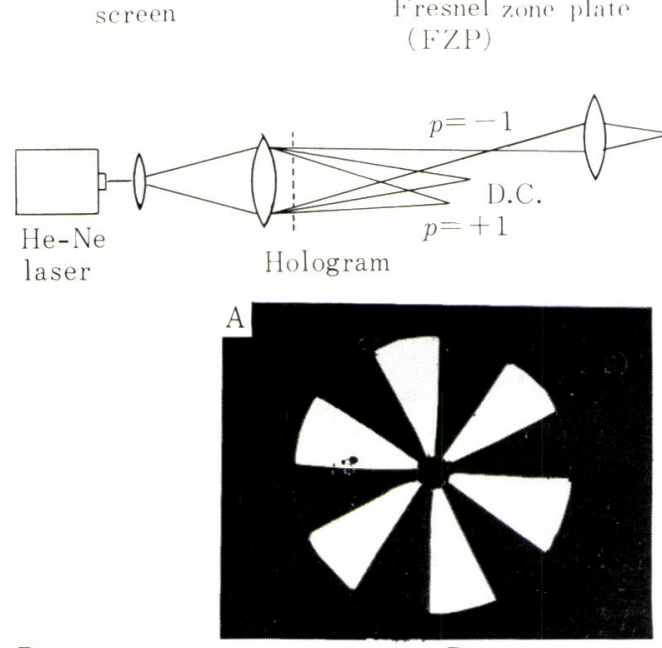

B
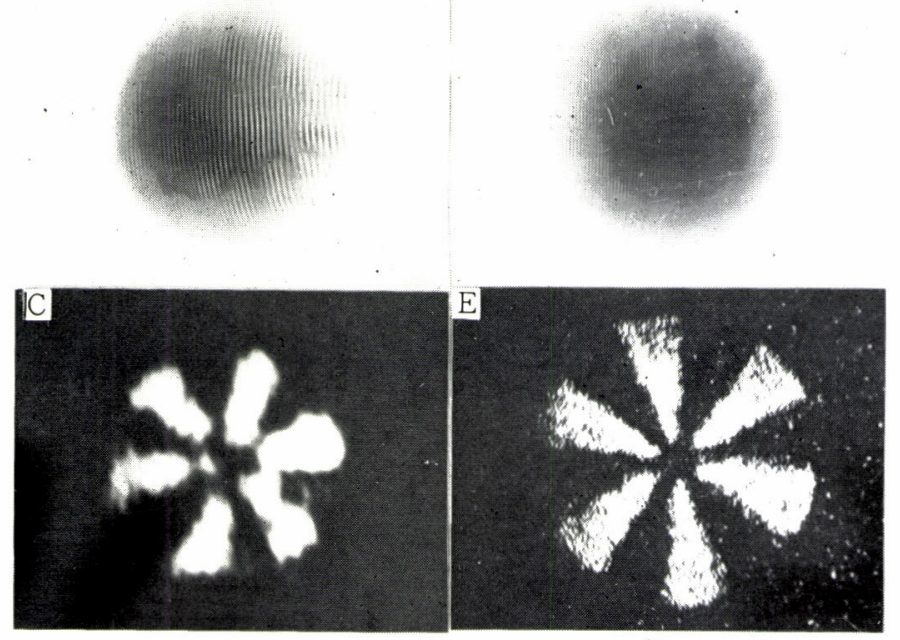

Fig. 5

Fig. 6 Fig.

Fig. $7 \quad(A \sim C)$

Fig. 7

$(\mathrm{A} \sim \mathrm{E}$

\begin{tabular}{c|c} 
& Fig. \\
Fig. 8 & 10 \\
$\mathrm{~A} \sim \mathrm{C}$
\end{tabular}

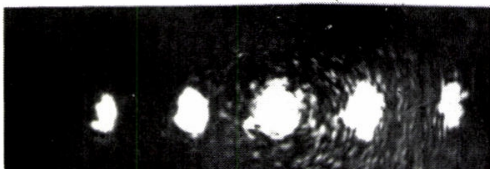

- $\Delta$,

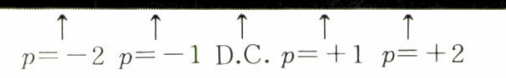

component

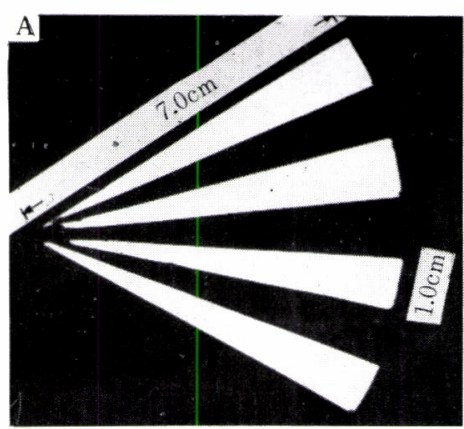

B

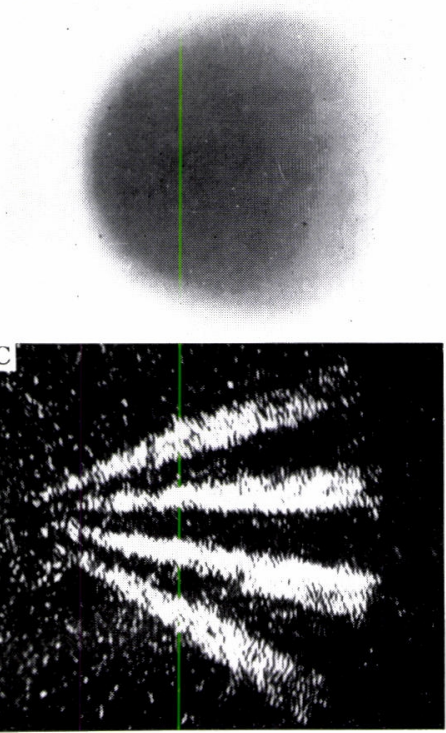

A

\section{GAMMA RAYS}

B

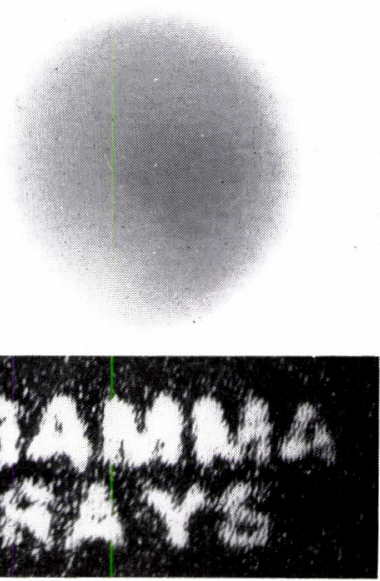


Fig. 5 Diagramatic explanation of hologram recording system.

Fig. 6 Diagramatic explanation of image reconstruction system.

Fig. 7 (A) Star phantom (object). (B) Hologram. (C) Reconstructed image from (B). Aperture ( $D=$ $r_{c}=8.0 \mathrm{~cm}, \nu_{c}=8.1 \mathrm{l} / \mathrm{cm}$ ), $u=17 \mathrm{~cm}, v=10 \mathrm{~cm}, \nu_{i / 2}=3.0 \mathrm{l} / \mathrm{cm}$ and $d=4.1 \mathrm{~mm}$. (D) Hologram.

(E) reconstructed image from (D). Aperture $\left(D=r_{c}=4.8 \mathrm{~cm}, \nu_{c}=23 l / \mathrm{cm}\right), u=v=10 \mathrm{~cm}, \nu_{1 / 2}$ $=9.0 \mathrm{l} / \mathrm{cm}$ and $d=1.4 \mathrm{~mm}$.

Fig. 8 Fourier spectrum of hologram.

Fig. 9 (A) Radial pattern phantom. (B) Hologram. (C) Reconstructed image. Aperture $\left(D=r_{c}=5.8\right.$ $\left.\mathrm{cm}, \nu_{c}=23 l / \mathrm{cm}\right), u=23 \mathrm{~cm}, v=10 \mathrm{~cm}, \nu_{1 / 2}=7.0 \mathrm{l} / \mathrm{cm}$ and $d=1.7 \mathrm{~mm}$.

Fig.10 (A) Object (negative for clarity). (B) Hologram. (C) Reconstructed image. Aperture $\left(D=r_{c}=5.8 \mathrm{~cm}, \nu_{c}=23 l / \mathrm{cm}\right), u=23 \mathrm{~cm}, v=10 \mathrm{~cm}, \nu_{1 / 2}=7.0 \mathrm{l} / \mathrm{cm}$ and $d=1.7 \mathrm{~mm}$.

were fabricated, from which off-axis FZPs of different $D, 5$ to $8 \mathrm{~cm}$, were cut out with $r_{c}$ fixed. For each $r_{1}$, therefore, $\nu_{c}$ is a fixed value. Half tone screens of a frequency range from 1.5 to $10 \mathrm{l} / \mathrm{cm}$ (lines per $\mathrm{cm}$ ) at $0.5 \mathrm{l} / \mathrm{cm}$ intervals were also fabricated. Using various combinations of them and varying $u$ and $v$, holograms of objects were recorded to examine how these variables affect the reconstructed image through comparison, and the off-axis FZP appropriate from the viewpoint of the spatial resolution was determined.

Figure 7(A) shows one of the objects used, a star phantom of $5 \mathrm{~cm}$ in outside diameter and $2.2 \mathrm{~cm}$ in each segment length; (B) is its hologram (actual size about $11 \mathrm{~cm}$ ) recorded using the an off-axis FZP of $r_{1}=1.0 \mathrm{~cm}, D=8.0 \mathrm{~cm}$, and $r_{c}=8.0 \mathrm{~cm}$, or of $\nu_{c}=8.0 \mathrm{l} / \mathrm{cm}\left(r_{16}\right.$ to $\left.r_{144}\right)$ and with a halftone screen of $\nu_{1 / 2}=3.0 \mathrm{l} / \mathrm{cm}$ placed close to this star phantom and at $u=17$ $\mathrm{cm}$ and $v=10 \mathrm{~cm}$. In reconstruction the image, as mentioned previously, this hologram must be reduced to about $7 \mathrm{~mm}$ in diameter, and Fig. 7 (C) shows a photograph of the reconstructed image. The theoretical resolution in this example is $d=4.1 \mathrm{~mm}$. Figure 7 (D) shows another hologram of the same object recorded using the off-axis FZP of $r_{1}=0.5 \mathrm{~cm}, D=r_{c}=5.8 \mathrm{~cm}, \nu_{c}=$ $23 \mathrm{l} / \mathrm{cm}\left(r_{33}\right.$ to $\left.r_{300}\right)$ and a half tone screen of $\nu_{1 / 2}$ $=9.0 \mathrm{l} / \mathrm{cm}$ and at $u=16 \mathrm{~cm}$ and $v=10 \mathrm{~cm}$; (E) is the image reconstructed from this hologram and $d=1.4 \mathrm{~mm}$ in this case. And, using same FZP, Figure 9 shows a case where the object is a radial pattern phantom, in which $u=23 \mathrm{~cm}$, $v=10 \mathrm{~cm}, \nu_{1 / 2}=7.0 \mathrm{l} / \mathrm{cm}$, and $d=1.7 \mathrm{~mm}$. Figure 10 is a case where letters of $2-\mathrm{mm}$ width and $1 \mathrm{~cm}$ high are the object, in which $u=23 \mathrm{~cm}$, $v=10 \mathrm{~cm}, \quad \nu_{1 / 2}=7.0 \mathrm{l} / \mathrm{cm}$, and $d=1.7 \mathrm{~mm}$; this means the width of lines constituting each letter is very close to the theoretical resolution.

In these examples, the actual resolution seems to be better than the theoretical resolution.

\section{Conclusions}

From the many experimental results obtained by optical simulation of the hologram recording system, of which are shown and discussed in Section 4, the authors conclude that:

(1) The off-axis zone plate having $D=r_{c}=$ $5.8 \mathrm{~cm}$ and $\nu_{c}=23 \mathrm{l} / \mathrm{cm}$ is sufficient for the reconstructed images.

(2) On the case of gamma-ray imaging, the off-axis FZP used as an aperture will be coarser than that mentioned above, due to the difficulties in manufacture.

\section{Acknowledgements}

The authors wish to thank Prof. K. Hisada for encouragement throughout this work. They also wish to thank Prof. M. Nakamura for his valuable advice in the discussion.

\section{References}

1) H.H. Barrett, D.T. Wilson and G.D. DeMeester: Opt. Commun., 5398 (1972)

2) H.H. Barrett and F.A. Horrigan: Appl. Optics, 12, 2686 (1973)

3) M.H. Formelant, G. DeMeester, D. Wilson and H.H. Barrett: J. Nucl. Med., 16, 188 (1974)

4) G. Itaya: 'Science of Light, 25, 79 (1976)

5) G. Itaya and K. Kojima: Radioisotopes, 27, 16 (1978)

6) A.R. Shulman: Optical Data Processing, Chapter 5 (Willy, New York, 1970) 
要 旨

\title{
軸外れフレネルソーン・プレートによる像形成の基礎的研究
}

\author{
板屋源清，小島一彦 \\ 金沢大学医療技術短期大学部 \\ 920 金沢市小立野5-11-80
}

軸外れフレネルゾーン・プレートは，搬送空間周波数として，ハーフトーン・スクリーンを使用 することによって，インコヒーレントな放射線線源の像形成に利用できる。このゾーン・プレート る符号化開口の一つであり。これによりホログラムを記録し、レーザ一光で再生画像を得る。

本報では, 光学的シミュレーションにより, 軸外れゾーン・プレートの構造, 像形成の方法找よ び基礎的問題について，物体，ホログラムおよびその再生像を示して，検討した。 